\title{
O Familiar envolvido no tratamento oncológico com os cuidados paliativos domiciliares
}

The family member involved in the oncology treatment regarding home-based palliative care

\author{
Taciana Lopes Bertholino* \\ Ana Cristina Nassif Soares ${ }^{* *}$
}

\begin{abstract}
Resumo:
Este artigo é resultado de uma pesquisa realizada para conclusão de mestrado. Os cuidados paliativos são uma modalidade de atendimento que têm avançado nos últimos anos, porém as construções literárias envolvendo os aspectos sociais dentro desta área não têm avançado nas mesmas proporções. O objetivo foi analisar a realidade do familiar envolvido no tratamento oncológico com os cuidados paliativos, a fim de compreender como estas famílias estão lidando com esta questão. A metodologia utilizada foi pesquisa qualitativa, através de estudos bibliográficos e entrevistas, respaldada pelo método do materialismo histórico-dialético. Foi evidenciado que as questões envolvendo a qualidade dos cuidados domiciliares são complexas e englobam vários fatores: sociais, emocionais, dinâmica interna da família, apoio da equipe e a maneira como suporta a morte.
\end{abstract}

Palavras-chave: Cuidados domiciliares. Cuidados paliativos. Família. Serviço Social

\begin{abstract}
:
This article is the result of a research performed for a master degree dissertation. The palliative care is a type of care that has been advancing in the last years even if the literature regarding its social aspects has not been evolving as fast. The main goal was to analyse the reality of the routine of the family member involved in the oncology palliative care, in order to understand how the families are dealing with it. in order to understand how the families are dealing with it. The methodology used was qualitative research, through bibliographic studies and interviews, based on the dialectical and historical materialsm method. We remarked that questions regarding the quality of the home care are complex and involve various factores such as: social class, feelings, family dynamics, team support and personal view of what death is.
\end{abstract}

Keywords: Home care. Palliative care. Family. Social policies. Social Work.

\footnotetext{
* Doutoranda do Programa de Pós-Graduação em Serviço Social - UNESP/Franca

** Profa Doutora da Graduação e Pós-Graduação do curso de Serviço Social - UNESP - Franca/SP
} 


\section{Introdução}

Este artigo é resultado de pesquisa realizada para conclusão de mestrado em Serviço Social. O interesse em se realizar esta pesquisa foi instigado por experiência profissional que tem proporcionado uma vivência direta com as dificuldades enfrentadas pelos familiares nos cuidados com pessoas em tratamento oncológico avançado, residentes no mesmo domicílio. A realidade tem mostrado alguns obstáculos que interferem na qualidade dos cuidados exercidos pelos familiares, tais como: elevação das despesas e diminuição da renda familiar, desgaste físico e emocional do cuidador, pressão dos hospitais para alta, políticas públicas insuficientes e burocratizadas, entre outros.

O objetivo deste estudo foi analisar a realidade do familiar envolvido no tratamento oncológico com os cuidados paliativos domiciliares, a fim de compreender como estas famílias estão arcando com esta situação.

Foram realizadas pesquisas de natureza bibliográfica e de campo (qualitativa), junto à Associação Brasileira de Assistências as Pessoas com Câncer (ABRAPEC), respaldada pelo método do materialismo histórico-dialético, sendo o materialismo histórico a representação do percurso teórico que mostra a dinâmica do real na sociedade e, a dialética o método de abordagem desta realidade, buscando compreender o processo histórico em seu próprio dinamismo (MINAYO, 2004). Segundo Paulo Netto (2011), o método dialético de Marx partiu criticamente da realidade objetiva e, a partir daí, iniciou uma análise da sociedade, para descobrir sua estrutura e dinâmica além da realidade aparente, buscando atingir a sua essência.

Após a aprovação do projeto de pesquisa pelo Comitê de Ética e Pesquisa, de acordo com o número 1.751.837, foi entrevistado no período de 30 de setembro a 14 de outubro 6 familiares cuidadoras, sendo todas do sexo feminino, com idades entre 33 e 58 anos, com renda per capita de até um salário mínimo e que estavam no exercício dos cuidados há mais de 1 mês. Todos os princípios éticos foram cumpridos e os procedimentos de sigilo e discrição foram seguidos. Sendo assim, os nomes que identificam os participantes da pesquisa neste artigo são fictícios.

Para explanar esta pesquisa, o artigo foi dividido em duas partes. Na primeira abordou- -se sobre os cuidados paliativos, buscando entender a sua essência e o papel da 
equipe multiprofissional, englobando o Serviço Social, que é uma profissão de essencial importância nesta equipe. Na segunda parte, fez-se uma breve abordagem sobre a família e o seu papel na contemporaneidade. Discorreu-se sobre os cuidados paliativos domiciliares, relacionando- -os com a rotina e as relações familiares.

\section{Cuidados Paliativos - o papel da equipe multiprofissional e do Serviço Social}

Os cuidados paliativos são um tipo de abordagem que busca oferecer cuidados multiprofissionais às pessoas com doenças que ameaçam a continuidade da vida, para que tenham qualidade de vida e uma morte digna:

A mensagem dos cuidados paliativos é: qualquer que seja a doença, não importa quão avançada esteja ou quais tratamentos já tenham sido recebidos, há sempre algo que pode ser feito para melhorar a qualidade de vida que resta para o paciente (GUIMARÃES, 2009, p. 17).

Valorizar uma abordagem que tem um olhar voltado ao ser humano é uma atividade desafiadora em uma sociedade contemporânea marcada pela valorização da infinitude da vida, de uma prática médica cartesiana onde o objetivo é sempre a cura da doença.

Os cuidados paliativos trazem uma proposta de desinstitucionalização da morte, integrando-a como um processo natural da vida, deixando de lado a tecnolatria e a priorização da vida biológica, no qual os instrumentos de cura e cuidado se transformam em ferramenta de tortura ou prolongamento exagerado da agonia, do sofrimento e morte do paciente (PESSINI, 2006).

Este tipo de abordagem possui princípios claros, que envolvem a complexa dimensão dos cuidados tanto com os pacientes quanto os familiares. De acordo com Matsumoto (2012), estes princípios são: alívio da dor e outros sintomas desagradáveis, considerar a morte como um processo natural e normal, não acelerar e nem adiar a morte; integrar os aspectos psicológicos e espirituais; oferecer condições para que o paciente viva ativamente até a sua morte; incluir os familiares no suporte da equipe; abordagem multiprofissional; melhorar a qualidade de vida e deve ser iniciado o mais precocemente possível.

Eles propõem a humanização através da abordagem interdisciplinar, desviando o olhar da doença para o ser humano na sua totalidade. Diversos profissionais compõem a 
equipe que, juntamente com a família dos pacientes, buscam uma terapêutica que lhes proporcione qualidade de vida até os momentos finais de suas vidas.

Segundo Souza e Bifulco (2010), a práxis da equipe deve se basear nos princípios dos cuidados paliativos, já citados anteriormente. E estes princípios trazem a importância da atenção dos profissionais à família, pois ela participa ativamente nas decisões e cuidados com o paciente, adquire uma rotina desgastante com sobrecarga emocional, que muitas vezes pode levar ao seu adoecimento. Ela precisa tomar decisões e providências práticas; criar espaços para diálogos; expressar sentimentos; ter um momento para perdão e reconciliação de mágoas.

Além disso, a equipe precisa oferecer um sistema de suporte para auxiliá-los no enfrentamento do luto:

[...] a busca pela qualidade de vida, ou pela dignidade de uma morte com menor sofrimento possível, torna-se imprescindível. Neste contexto, não somente o paciente passa a ser alvo de todos os cuidados multiprofissionais, como também todos os seus familiares e cuidadores passam a ser vistos como agentes cujo sofrimento deve ser amenizado. A humanização na área do câncer obriga os profissionais a saberem lidar, tanto com os pacientes que estão vivendo à expectativa de um diagnóstico, quanto com aqueles que estão sucumbindo à doença, bem como com todos seus familiares e cuidadores (FERNANDES, 2010, p. 6).

É importante que os profissionais aprimorem suas habilidades de comunicação (verbal e não verbal), sendo a escuta uma das principais habilidades a ser desempenhada, " [...] as vezes só é necessário estarmos presentes, o não fazer já é, por si só, uma ação" (SAPORETTI et al., 2012, p. 49).

Diante deste contexto, é essencial trazer uma reflexão sobre a importância do trabalho do assistente social na equipe de cuidados paliativos e a sua especificidade, pois, observou-se durante a pesquisa que a atuação do profissional nesta área ainda é bem pouco explorada.

O assistente social é um profissional da área da saúde e segundo Martinelli (2002), a relação do profissional com a área é bastante intensa e histórica, sendo constitutiva de sua identidade profissional.

Contudo pela peculiaridade que se reveste a sua ação interventiva no campo das relações sociais, e pela própria forma de ser de sua identidade, onde se articulam dimensões ético-políticas, teórico-metodológicas e técnico-operativas, o Serviço Social tem uma contribuição essencialmente importante na perspectiva da 
realização de processos e trabalhos interdisciplinares que tenham por referência os sujeitos sociais com os quais atuamos (MARTINELLI, 2002, p. 7).

O Serviço Social tem sua atuação voltada para a compreensão e enfrentamento das expressões da questão social, que segundo lamamoto (2007), são o objeto de trabalho do assistente social. Questão social compreendida como “[...] conjunto das expressões das desigualdades da sociedade capitalista madura" (IAMAMOTO, 2007, p. 27). Os assistentes sociais trabalham com vários tipos destas expressões, tais como desemprego, habitação, saúde, entre outras. A autora afirma que questão social é desigualdade e rebeldia, pois envolve quem vive estas desigualdades e também luta se opondo a elas.

No âmbito da saúde, busca atuar "[...] tanto de acordo com os princípios discutidos e preconizados pelos defensores da Reforma Sanitária como pelos dispostos no Código de Ética que rege a profissão" (SIMÃO et al., 2010, p. 159).

As propostas do Sistema Único de Saúde (SUS) vão em direção aos princípios do projeto ético-político e com a Lei de Regulamentação da Profissão, que norteiam e orientam a atuação do profissional. O projeto profissional luta pela efetivação da democracia e da cidadania e isso envolve a busca pela efetivação e ampliação dos serviços públicos universais e de qualidade, com controle por parte da sociedade nos assuntos e decisões que lhe envolve. De acordo com lamamoto (2007) isso é adquirido pela democratização das informações, dos direitos e acompanhamento das decisões nos espaços coletivos que permitem a ampliação destes direitos.

De acordo com Vasconcelos (2003), o assistente social na saúde é um dos principais articuladores de equipes multiprofissionais; sua prática deve ser voltada para o coletivo, com ações que objetivem a ampliação e universalização de direitos, levando a uma transformação que priorize os interesses da maioria. No exercício profissional, a prioridade é a ação projetada e realizada a partir da reflexão sobre o real.

Concorda-se com a autora ao afirmar que na saúde cabe aos assistentes sociais: planejar, desenvolver e divulgar os conhecimentos e informações necessárias sobre todos as vertentes históricas e da conjuntura, relacionados à saúde, à participação social e política dos usuários, a partir dos novos conhecimentos que a ciência tem gerado sobre a realidade social. De acordo com o Conselho Federal de Serviço Social (2014), as ações predominantes no 
Serviço Social são as socioassistenciais, as de atuação interdisciplinar e as intervenções socioeducativas.

O profissional precisa ter clareza do seu papel e de suas atribuições, inclusive junto à equipe de saúde para poder desenvolver ações conjuntas, pois:

\footnotetext{
O assistente social, ao participar de trabalho em equipe na saúde, dispõe de ângulos particulares de observação na interpretação das condições de saúde do usuário e uma competência também distinta para o encaminhamento das ações, que diferencia do médico, do enfermeiro, do nutricionista e dos demais trabalhadores que atuam na saúde (CONSELHO FEDERAL DE SERVIÇO SOCIAL, 2014, p. 44).
}

Destarte, o assistente social é um profissional que dentro do trabalho de cuidados paliativos, ocupa um lugar na equipe e diante dela, deve se destacar pela sua especificidade. Fortalece a defesa da garantia de direitos do paciente e familiares, considerando que os cuidados paliativos têm o objetivo de respeitar a integridade pessoal, dignificando e garantindo que suas necessidades básicas sejam honradas

De acordo com Souza e Bifulco (2010), as intervenções do Serviço Social com pessoas em tratamento paliativo devem atender às necessidades sociais dos paciente e da família, trabalhar o luto antecipatório, possibilitar que "questões pendentes" possam ser resolvidas, facilitar a comunicação entre paciente, família e equipe, trabalhar o luto familiar após o óbito, proporcionar que o paciente administre seu tempo restante de vida, orientar e democratizar as informações sobre os direitos sociais, entre outras. A autora cita também, que o assistente social e a equipe jurídica podem auxiliar o paciente e seus familiares quanto às questões de bens, curatelas, procurações, seguros e auxílios governamentais destinados aos pacientes fora das possibilidades terapêuticas de cura.

A interdisciplinaridade, segundo Martinelli (2002) é um processo de ações, decisões e relações socializadas com os membros da equipe. Esta socialização é essencial quando se trata de cuidados paliativos, já que este tem como objetivo a qualidade de vida da pessoa até os momentos finais de sua vida, trabalhando os fatores físicos, sociais, emocionais e espirituais. Na prática, o assistente social junto aos outros membros da equipe, trabalha para fortalecer o sistema de apoio ao paciente, prevenindo situações de abandono e/ou limitações para que ele se sinta respeitado e valorizado. O profissional também auxilia no resgate da dignidade, que muitas vezes, devido a impossibilidade de cura da doença é perdida (SIMÃO et al., 2010). 
Teixeira e Nunes (2012) citam que a interdisciplinaridade pode colaborar para a evolução da atenção qualitativa, visando a maior satisfação do usuário ao serviço, no entanto a equipe precisa ser diversificada, com formação que possa trazer conhecimentos que se completam tanto ao clínico, epidemiológico como ao social. Isso pode representar a compreensão de um trabalho coletivo, priorizando práticas reflexivas e democráticas, “[...] em que se percebe a família dialeticamente, construída histórica e socialmente, como sujeitos coletivos, que também fazem a história de sua sociedade, de sua época" (TEIXEIRA; NUNES, 2012, p. 141).

As mesmas autoras dizem que esta concepção de trabalho exige uma prática sanitária visando a atenção integral, para isso o espaço de ação deve ser intersetorial e interdisciplinar, pois os indivíduos são sujeitos sociais e o processo de adoecer envolve determinações sociais. Portanto, é preciso que haja troca de saberes, porque somente a saúde não dará conta.

A intervenção do Serviço Social em cuidados paliativos deve voltar-se não apenas para a pessoa em tratamento, mas também para a família, pois além dela enfrentar todas as dificuldades do contexto social e desgaste emocional em relação ao enfrentamento de uma doença grave, muitas vezes é sobrecarregada por ter que exercer a função dos cuidados no lar.

Ademais, é preciso saber lidar com a proximidade da morte:

A morte é um evento que todos temos que enfrentar, sejam quais forem nossas crenças. As percepções da morte e do processo do morrer e as formas de reação a esse fato variam de acordo com a sociedade em que vivemos e com o período histórico e a cultura em que estamos inseridos (GUIMARÃES, 2009, p. 18).

Para conviver com pessoas em tratamento paliativo é preciso encarar a morte como algo natural e buscar junto à equipe profissional, que ela seja um processo tranquilo, com dignidade e com aceitação. Essa condição é difícil, pois a sociedade brasileira contemporânea, diante dos avanços tecnológicos na área da saúde, tem idealizado a vida como infinita.

Apesar do profissional trabalhar com a família questões que envolvem o óbito, é preciso deixar claro que não é função do assistente social realizar a comunicação do óbito aos familiares. A intervenção do assistente social é realizada somente após a comunicação deste óbito já ter sido realizada pelo médico que acompanhou o processo. 
O Conselho Federal de Serviço Social (2014) traz também outras funções que não devem ser realizadas pelos assistentes sociais na área da saúde como um todo, tais como agendamento de consultas e exames, requisição de ambulância para transporte e alta, levantamento de vagas em outras unidades de saúde para realizar transferência hospitalar, elaboração de declaração de comparecimento na unidade quando o atendimento não for realizado pelo assistente social. Além disso:

Não cabe ao profissional de Serviço Social se utilizar no exercício de suas funções de terapias individuais, de grupos, de família ou comunitárias, mas sim potencializar a orientação social com vistas à ampliação do acesso dos indivíduos e da coletividade aos direitos sociais (CONSELHO FEDERAL DE SERVIÇO SOCIAL, 2014, p. 42).

Segundo Bravo e Matos (2012), o assistente social busca estudos na área da saúde e muitas vezes, passa a realizar outras funções, como direção de unidade, gerência etc, distanciando-se das atividades do assistente social. Então, o profissional acaba exercendo apenas ações que lhes são transferidas historicamente pela divisão de trabalho em saúde.

É importante destacar que os profissionais que compõem a equipe de cuidados paliativos precisam ter conhecimento e capacidade de analisar o contexto social que envolve os pacientes e seus familiares. $O$ assistente social possui uma capacidade de percepção e leitura da realidade social, que são essenciais neste tipo de atuação colaborando assim, na melhoria da qualidade de vida destas pessoas.

\section{Cuidados paliativos domiciliares e as relações familiares}

A composição familiar é mutável e se transforma conforme o desenvolvimento da sociedade e seu sistema econômico. De acordo com Engels (1985, p. 42), "a família se constitui conforme a realidade de uma sociedade em uma determinada época e, vai se modificando no processo histórico e social".

Segundo o autor, ao longo da história, a família passou por diversas formações até chegar ao modelo nuclear, sendo a economia um fator essencial na influência das formações e transformações destas famílias.

Atualmente, apesar das famílias tornarem-se mais variadas e complexas (famílias reconstituídas, monoparentais, compostas por casais homossexuais com ou sem filhos, casais sem filhos, entre outras), as características do modelo nuclear continuam presentes. 
Foi vivenciado uma transformação na instituição familiar, nota-se a emersão de novas maneiras de ser entre homens e mulheres e seus filhos, compartilhados por diversos casais e que levarão à construção de novas regras (SZYMANSKI, 2002). Esta autora afirma que estas transformações da vida conjugal, se expressam pelo aumento da monoparentalidade, da taxa de divórcios e recasamentos.

Outras características significativas da família contemporânea são: o aumento no número de divórcios, diminuição dos casamentos formais, do número de filhos com mulheres ou casais que não desejam tê-los e aumento do número de famílias unipessoais. Para Gueiros (2002), estas características tornam estas configurações mais complexas.

Para esta pesquisa buscou-se trabalhar com famílias de diversas composições, compreendendo-as para além do modelo tradicional (pai, mãe e filhos). Sawaia (2014) traz que, para compreender e trabalhar com a família, deve-se olhar para esse grupo como um núcleo em que as pessoas se unem por razões afetivas e que dividem seu cotidiano.

A Política Nacional de Assistência Social (PNAS) considera as diversas formações familiares respaldadas pelas relações afetivas, destacando sua função no âmbito dos cuidados. No entanto, Mioto e Prá (2015) afirmam que a contrarreforma do Estado a partir dos anos 1990 vem trazendo retrocessos para as conquistas da Constituição Federal de 1988, levando à privatização da seguridade social e com isso, as famílias vêm sendo cada vez mais cobradas pelo suprimento do bem-estar: "Nesse contexto é que se instaura o debate sobre os processos de responsabilização da família no campo da política social” (MIOTO; PRÁ, 2015, p. 149).

Para Gelinski e Moser (2015), o ponto essencial é que, mesmo a família sendo o centro das políticas sociais, o Estado vem se isentando das suas responsabilidades e transferindo-as para o núcleo familiar:

O contexto em que emerge, como já foi dito e é conhecido por todos, é o do neoliberalismo, caracterizado pelo Estado mínimo, capital volátil, crise de emprego, aumento da miséria, manipulação comercial e publicitária de corpos e sentimentos. As instituições não mais promovem modelos de identificação e confiabilidade, e o indivíduo está fechado em si mesmo, encastelado e autoabsorto em seu narcisismo. Nesse contexto, o Estado, isentando-se dos deveres de prover o cuidado dos cidadãos, sobrecarrega a família, conclamando-a a ser parceira da escola e das políticas públicas, e a sociedade, atônita, na ausência de "lugares com calor", elegea como o lugar de proteção social e psicológica (SAWAIA, 2014, p. 54). 
Diante disso, chama a atenção a contradição em que a família encontra-se inserida no atual contexto das políticas sociais, pois ao mesmo tempo em que é prioridade na atenção, também está sendo cobrada e responsabilizada por cuidar da vida das pessoas.

Concorda-se com Mioto e Prá (2015), quando afirmam que este fator percorre o caminho inverso dos direitos sociais, pois representam a privatização da seguridade social e possuem um caráter familiarista, que marcou historicamente as políticas sociais brasileiras. 0 familismo considera que as famílias são as principais responsáveis pelo bem-estar de seus componentes em detrimento do Estado.

O envolvimento da família durante todo o processo dos cuidados paliativos é essencial, principalmente quando estes cuidados são exercidos no domicílio.

A experiência profissional faz concordar com Duarte, Fernandes e Freitas (2013), ao afirmarem que os cuidados paliativos domiciliares trazem desafios significativos e constantes aos familiares, provocando graves consequências. "O ato de cuidar de um doente pode ser sentido como uma tarefa que pode provocar desequilíbrio, sobrecarga física, emocional, social e econômica, apesar do desejo e satisfação de exercer este papel" (RIBEIRO; SOUZA apud DUARTE; FERNANDES; FREITAS, 2013, p.2).

A responsabilização da família nos cuidados vem se tornando cada vez mais naturalizada e o "[...] uso instrumental da família pela política social através da ênfase na solidariedade e no cuidado. O cuidado calcado numa concepção de amor ao próximo e atitude de humanidade" (MIOTO; PRÁ, 2015, p. 165).

De acordo com Duarte, Fernandes e Freitas (2013), a família quando assume os cuidados em domicílio passa a exercer funções novas, que eram desconhecidas anteriormente tais como, administrar e manusear medicamentos, drenos, sondas, fazer curativos, trocar fraldas, aprender a lidar com o agravamento da doença, agendamento e acompanhamento nas consultas e proximidade com a morte. Por isso, a equipe de saúde precisa conhecer e ter proximidade com o cuidador familiar. Para Soratto (2013), os cuidadores familiares precisam de autocuidado e suporte da equipe, pois eles enfrentam sentimentos de tristeza, insegurança ao realizarem as atividades dos cuidados, culpa, solidão, privação do convívio familiar, de lazer e financeiro.

As atividades desempenhadas no ato de cuidar são intensas e rotineiras, e segundo Duarte, Fernandes e Freitas (2013), são realizadas na sua maioria por mulheres. Além disso, a escolha do cuidador pelos familiares está relacionada aos fatores de afetividade entre os 
membros, grau de parentesco, proximidade residencial, entre outros. No entanto, a autora ressalta que estes fatores não são preponderantes, pois nem sempre existe um acordo familiar na escolha do cuidador. Ele pode ser escolhido pelos demais familiares, pelo próprio paciente ou também pode acabar assumindo a função pela falta de opção.

Lopes (2014) aponta que sua experiência profissional e vários estudos literários comprovam que se tornar cuidador, nem sempre é uma opção. A falta da escolha acaba impondo ao familiar o desempenho desta atividade. Esta imposição pode ser resultado das dificuldades financeiras que impossibilitam a família de contratar um cuidador profissional ou das próprias questões internas da dinâmica familiar que impedem que outras pessoas assumam essa condição.

Esta falta de opção fica clara quando um dos sujeitos conta sobre o porquê se tornou cuidadora:

\begin{abstract}
Porque ninguém se interessou. Eu tenho uma irmã 4 anos mais nova que mora lá perto de casa. Ela tem um menininho de quase 2 anos, tem uma menininha de 5 e tem essa maior de 16 anos que é a que dorme com meu pai de 2 a 3 vezes por semana. Venho pedindo pra minha irmã me dar uma ajuda durante a semana. Pelo menos umas 2 vezes por semana, levar meu pai um pouquinho pra casa dela na parte da tarde, porque meu cunhado trabalha um dia sim e um dia não, que meu pai fique pelo menos umas 3 horas na casa dela, que seja pra eu correr com o serviço ou que seja pra eu não fazer nada. Mas uma, pra ela adquirir responsabilidade com meu pai e outra, pra eu descansar um pouco (Léa, cuidadora do pai).
\end{abstract}

No caso de Léa, observa-se que houve falta de interesse por parte de sua família e ela acabou assumindo a função sozinha. Ela tenta envolver sua irmã para Ihe auxiliar nos cuidados e assim, tentar diminuir a sobrecarga e o desgaste que a atividade tem lhe causado, mas continua realizando tudo sozinha.

Os cuidados domiciliares provocam mudanças drásticas na rotina e nos papéis familiares, inclusive em um aspecto que é essencial no desempenho destas atividades - o socioeconômico:

Muito embora os pacientes sejam acompanhados por instituições pertencentes ao SUS, a permanência no domicílio requer a organização e o provimento de materiais necessários para a efetivação do cuidado. Cadeira de rodas e de banho, cama hospitalar, fraldas, insumos para curativos, sondas, enfim, são instrumentos que, mediante a ausência de políticas públicas voltadas aos cuidados de fim da vida, acabam sendo providenciados pelas próprias famílias (LOPES, 2014, p. 76).

Para Duarte, Fernandes e Freitas (2013) o ato de cuidar de pessoas fora da possibilidade de cura de uma doença, é uma atividade diária e repetitiva, pois os pacientes 
precisam de cuidados integral e permanente. Em alguns casos estes cuidados são exercidos de maneira solitária e sem descanso. Além disso, estas atividades, muitas vezes, são realizadas juntamente com outras tarefas domésticas.

Nota-se a intensidade dos cuidados domiciliares presentes no cotidiano das cuidadoras desta pesquisa ao contarem detalhadamente sobre as suas rotinas:

\begin{abstract}
As 8 horas da manhã eu acordo ele pra dar o leite com suplemento e a medicação da manhã, aí eu tiro a fralda dele e se vazou na cama, eu troco a cama, troco ele, tiro a fralda dele, dou o suplemento, faço em média meia hora de fisioterapia nele, que está tendo que fazer todo dia e dou a medicação. [..] Geralmente ele dorme até as 11h30-12 h. Quando eu estou muito cansada eu durmo com ele de novo, mas geralmente não é o que eu faço, eu peço pra minha mãe deitar com ele e vou cuidar do serviço de casa. A hora que ele acorda eu dou um banho nele, um banho bem caprichado e a minha mãe dá o almoço. A comida dele a minha mãe ainda está dando conta de cuidar, mas é a única coisa que ela dá conta de fazer. Ela dá o almoço dele e eu continuo os serviços de casa e ela fica sentadinha com ele na varanda. Eu vou dando o suporte, vou levantando ele a cada 2 horas, vê se ele quer uma água, isso tudo eu vou me dividindo. Eu pareço uma barata tonta, né. Geralmente dou um suco pra ele na parte da tarde, lá pelas 16 horas. A 18 horas eu dou um outro banhozinho nele. [...] Logo em seguida eu dou a medicação da noite, a minha mãe dá a janta, que é papa. Já arrumo todo o quarto e vou lavar uma louça, vou juntar o lixo, vou fazer um café, vou recolher a roupa que já lavei de manhã, tem que recolher a roupa pra no outro dia estender de novo. Aí eu vou tomar um banho. Aí dá o que? Quando é 20 h30 mais ou menos ele já está sentindo sono, aí eu ponho ele na cama. [...] Aí as $23 \mathrm{~h}$ eu ponho fralda e dou a primeira virada nele, aí depois as $2 \mathrm{~h}$ da manhã, as $5 \mathrm{~h}$ da manhã e as $8 \mathrm{~h}$ da manhã. Então, se não troco ele as $2 \mathrm{~h}$ da manhã, eu tenho que trocar as 5 horas (Léa, cuidadora do pai).
\end{abstract}

A riqueza de detalhes faz com que haja aproximação sutil do cotidiano de Léa, tentando imaginar como o corpo se sente ao acordar várias vezes a noite e no dia seguinte ter que seguir com o trabalho, sem pausa para o descanso.

O agravamento do estado clínico e a proximidade da morte podem elevar o nível de estresse do cuidador familiar. Durante o trabalho diário, foi notado também que em alguns casos o paciente percebe o sofrimento do cuidador familiar, e isso acaba atingindo-o e causando-Ihe mais sofrimento e dor.

Apesar desta contextualização, realizar a atividade de cuidar também pode trazer sentimentos positivos como gratificação, satisfação e crescimento pessoal, e muitas vezes o cuidador prefere estar ao lado da pessoa doente, devido à relação de afeto existente entre eles (DUARTE; FERNANDES; FREITAS, 2013). Foi observado esta característica na fala de Hirana (sujeito da pesquisa): 
Eu prefiro eu cuidando dele do que um estranho, porque eu sei que comigo ele está bem cuidado. Com estranho eu não sei como seria, se ia cuidar igual a gente cuida, porque tem mais paciente, mais pessoas, então não cuida como a gente e sem contar o amor também, né, o carinho (Hirana, cuidadora do irmão).

No relato de Hirana fica evidente a preocupação dela em relação ao irmão ser cuidado por uma pessoa desconhecida e diz preferir que ele fique com a família, pois além dos cuidados também recebe carinho.

Analisando estas histórias e as contribuições literárias sobre a temática, assim como Duarte, Fernandes e Freitas (2013), percebe-se que além dos pacientes, a família também possui demandas que precisam ser conhecidas e cuidadas, pois o processo de cuidar afeta a estrutura e a dinâmica familiar. Destarte:

\footnotetext{
É necessário atentar aos padrões culturais deste indivíduo, família e comunidade, respeitando suas tradições, hábito, sentimentos e necessidades, a fim de enaltecer a humanização e a autonomia dos envolvidos no cuidar. O sucesso do cuidado domiciliar está em olhar o indivíduo e sua família em seu contexto, visualizando e considerando seu meio social, suas inserções, seu local de moradia, seus hábitos e relações e qualquer outra coisa ou situação que faça parte de seu existir e estar no mundo (SORATTO, 2013, p. 11).
}

Portanto, deve haver um olhar para a realidade social em que estas famílias estão inseridas, pois todo este contexto influencia diretamente nas suas relações sociais e de cuidados.

\section{Conclusão}

A pesquisa que realizada trouxe vários conhecimentos e reflexões acerca da temática proposta. Buscou-se com este estudo analisar a realidade do familiar envolvido no tratamento oncológico com os cuidados paliativos domiciliares, para compreender como estes familiares lidam com essa realidade. Através dos relatos de seis familiares cuidadores e do estudo teórico de vários temas, tais como cuidados paliativos, família, cuidados domiciliares, relações de gênero nos cuidados e morte, foi observado que cuidar de um familiar no limite entre a vida e a morte não é uma tarefa fácil e deve envolver não somente a família, mas também, a equipe multiprofissional e o Estado.

Presenciou-se que os cuidados paliativos trazem uma proposta de atendimento humanizado através de uma equipe multiprofissional, focado na qualidade de vida do ser humano até os momentos finais de sua vida. Esta equipe deve ser multiprofissional numa 
abordagem interdisciplinar, envolvendo a participação dos familiares, buscando priorizar a vontade do paciente.

A equipe precisa oferecer suporte à família, pois ela muitas vezes, participa ativamente nas decisões e nos cuidados com os pacientes, adquirindo uma nova e desgastante rotina. É necessário que haja espaços para resolver questões pendentes entre os familiares e o paciente, reconciliação de mágoas, pois nem sempre quem está doente é amado por todos da família, os vínculos familiares podem estar fragilizados.

O Serviço Social é uma profissão que se faz presente na equipe de cuidados paliativos e é extremamente importante, pois trata-se de um profissional da área da saúde com capacidade para escuta e leitura da realidade social, estendendo sua intervenção aos familiares.

Para estudar sobre os cuidados domiciliares desempenhados por cuidadores familiares, foi realizado um estudo sobre a família e presenciado que sua composição foi se modificando com o processo histórico, social e econômico. Atualmente, vivencia-se transformações na instituição familiar com diversidade nas composições.

A família possui um papel de destaque na Política Nacional de Assistência Social, porém devido à contrarreforma do Estado, as famílias estão sendo cada vez mais cobradas pelo suprimento do bem-estar da pessoa em tratamento. Portanto, a família está inserida em um contexto contraditório, em que é prioridade na atenção pública e ao mesmo tempo está sendo cobrada e responsabilizada por cuidar da doença avançada de seus familiares. O Estado vem transferindo a responsabilidade dos cuidados para as famílias que, por sua vez, precisa ser ampara pelo mesmo para oferecer cuidados adequados aos seus familiares. Isso mostra que definir a responsabilização pelos cuidados de um ser humano não se limita somente à família, mas envolve também o Estado que vem se esquivando de tal compromisso.

Em relação aos cuidados domiciliares, através dos estudos teóricos e dos relatos dos sujeitos, observou-se que eles trazem desafios aos familiares e provocam grandes consequências sociais, físicas e emocionais. Constatou-se que a família passa a exercer novas funções voltadas aos cuidados que, até então, eram desconhecidas. A rotina dos cuidados é intensa, ininterrupta e a escolha do cuidador pode estar relacionada aos fatores de afetividade, grau de parentesco ou até mesmo ser assumida por falta de opção. 
Nos relatos de suas rotinas diárias foi notado que as cuidadoras deixaram de viver suas próprias vidas e foram tomadas por uma rotina sobrecarregada de desgaste físico, emocional e social. Sendo assim, exercer a função de cuidados domiciliares interfere no autocuidado do cuidador, que muitas vezes é deixado de lado.

Percebe-se que o processo de cuidar afeta toda a dinâmica familiar e o segredo do sucesso destes cuidados está relacionado em cuidar tanto do paciente quanto da família enxergando-os em seu contexto social, seu local de moradia, suas relações familiares e comunitárias ou qualquer outro fator que esteja relacionado à sua história de vida. Além disso, esta família precisa estar amparada pelas políticas públicas e pela equipe de saúde, para que tenha respaldo para exercer esta função e não adoecer física, emocional e economicamente.

\section{REFRÊNCIAS}

BRASIL. Ministério do Desenvolvimento Social e Combate à Fome. Política Nacional de Assistência Social. Brasília, DF, 2005. Disponível em: <http://www.mds.gov.br/webarquivos/ publicacao/assistencia_social/Normativas/PNAS2004.pdf>. Acesso em: 26 dez. 2016.

BRAVO, Maria Inês; MATOS, Maurílio Costa. Reforma sanitária e projeto ético-político do Serviço Social: elementos para o debate. In: . (Org.). Saúde e Serviço Social. São Paulo: Cortez, 2012.

CONSELHO FEDERAL DE SERVIÇO SOCIAL. Parâmetros para a atuação de assistentes sociais na Política de Saúde. Brasília DF, 2014.

DUARTE, Itala Villaça; FERNANDES, Krícia Frogeri; FREITAS, Suellen Cristo de. Cuidados paliativos domiciliares: considerações sobre o papel do cuidador familiar. Revista da Sociedade Brasileira de Psicologia Hospitalar, Rio de Janeiro, v. 16, n 2, p. 73-88, jul./dez. 2013. Disponível em: <http://pepsic.bvsalud.org/pdf/rsbph/v16n2/v16n2a06.pdf>. Acesso em: 29 dez. 2016.

ENGELS, Friedrich. A origem da família, da propriedade privada e do Estado. Lisboa: Presença. 1985

FERNANDES, Hézio Jadir. Dissecando e desmistificando o câncer. In: BIFULCO, Vera Anita; FERNANDES, Hézio Jadir; BARBOZA, Alessandra Bigal. (Coord.). Câncer: uma visão multiprofissional. Barueri: Minha Ed. 2010.

GELINSKI, Carmem Rosário Ortiz Gutierrez; MOSER, Liliane. Mudanças nas famílias brasileiras e a proteção desenhada nas políticas sociais. In: MIOTO, Regina Célia; CAMPOS, Marta Silva; CARLOTO, Cássia Maria. (Org.). Familismo: direitos e cidadania. São Paulo: Cortez, 2015. 
GUEIROS, Dalva Azevedo. Família e proteção social: questões atuais e limites da solidariedade familiar. Serviço Social \& Sociedade. São Paulo, ano 23, n. 71, p. 102-121, esp. 2002.

GUIMARÃES, Regina Maria. Filosofia dos cuidados paliativos. In: SALTZ, Ernani; JUVER, Jeane (Org.). Cuidados paliativos em oncologia. Rio de Janeiro: Ed. Senac Rio, 2009.

IAMAMOTO, Marilda V. O Serviço social na contemporaneidade: trabalho e formação profissional. São Paulo: Cortez, 2007.

LOPES, Fernanda. A possibilidade assistencial das famílias dos pacientes em cuidados paliativos: dinâmicas internas e relação com o contexto das políticas púbicas. 2014. 195 f. Dissertação (Mestrado em Serviço Social) - Pontifícia Universidade Católica de São Paulo, São Paulo, 2014.

MARTINELLI, Maria Lúcia. Serviço Social em Hospital-Escola: um espaço diferenciado de ação profissional. Serviço Social e Saúde. Campinas, ano 1, n. 1, p. 1-12, jan./dez. 2002.

MATSUMOTO, Dalva Yukie. Avaliação do paciente em cuidados paliativos. In: CARVALHO, Ricardo Tavares; PARSONS, Henrique Afonseca. (Org.). Manual de cuidados paliativos ANCP. 2. ed. ampl. e atual. São Paulo: ANCP, 2012. Disponível em: <http://www.paliativo.org.br/ noticias/tag/manual-de-cuidados-paliativos-ancp/>. Acesso em: 20 out. 2016

MINAYO, Maria Cecília de Souza. O desafio do conhecimento: pesquisa qualitativa em saúde. São Paulo: Hucitec, 2004.

MIOTO, Regina Célia Tamaso; PRÁ, Keli Regina Dal. Serviços sociais e a responsabilização da família: contradições da política social brasileira. In: ; CAMPOS, Marta Silva;

CARLOTO, Cássia Maria (Org.). Familismo: direitos e cidadania. São Paulo: Cortez, 2015.

PAULO NETTO, José. Introdução ao estudo do método de Marx. São Paulo: Expressão Popular, 2011.

PESSINI, Leo. Bioética, envelhecimento humano e dignidade no adeus à vida. In: FREITAS, Elizabete V. de; PY, Lígia (Ed.). Tratado de geriatria e gerontologia. 2. ed. Rio de Janeiro: Guanabara Koogan, 2006.

SAPORETTI et al. Diagnóstico e abordagem do sofrimento humano. In: CARVALHO, Ricardo Tavares; PARSONS, Henrique Afonseca. (Org.). Manual de cuidados paliativos ANCP. 2 ed. ampl. Ed. atual. São Paulo: ANCP. 2012.

SORATTO, Maria Tereza. As dificuldades de enfrentamento do familiar de paciente em cuidados paliativos. Saúde em Revista, Piracicaba, v. 13, n. 34, p. 7-17, maio/ago. 2013.

SAWAIA, Bader B. Família e afetividade: a configuração de uma práxis ético-política, perigos e oportunidades. In: ACOSTA, Ana Rojas; VITALE, Maria Amalia Faller. (Org.). Família: redes, laços e políticas públicas. São Paulo: Cortez, 2014. 
SIMÃO, Andréa Branco et al. A atuação do Serviço Social junto a pacientes terminais: breves considerações. Serviço Social \& Sociedade, São Paulo, n. 102, p. 152-164, abr./jun. 2010.

SOUZA, Milena dos Reis Bezerra; BIFULCO, Vera Anita. Planejando o futuro: como os cuidados paliativos podem ajudar o paciente com câncer. In: BIFULCO, Vera Anita; FERNANDES, Hézio Jadir; BARBOZA, Alessandra Bigal. (Coord.). Câncer: uma visão multiprofissional. Barueri: Minha Ed. 2010.

SZYMANSKI, Heloisa. Viver em família como experiência de cuidado mútuo: desafios de um mundo em mudança. Serviço Social \& Sociedade, São Paulo, ano 23, n. 71, p. 9-25, esp. 2002.

TEIXEIRA, Mary Jane; NUNES, Sheila Torres. A interdisciplinaridade no programa saúde da família: uma utopia? In: BRAVO, Maria Inês Souza et al. (Org.). Saúde e Serviço Social. São Paulo: Cortez, 2012.

VASCONCELOS, Ana Maria. A prática do Serviço Social: cotidiana, formação e alternativas na área da saúde. São Paulo: Cortez, 2003.

Recebido em: 09.10.2019

Aceito em: 03.04.2020 